\title{
Smile Mumias: oral health education and dental care for children in Mumias District, Western Kenya (formerly the Akhonya Dental Project): one year on
}

Please send any ideas for feature articles for consideration to:

Rowena Milan,

British Dental Journal,

The Macmillan Building,

4-6 Crinan Street

London

N1 9XW

Email:r.milan@nature.com

\section{S. Barber ${ }^{1}$}

This article outlines the progress made in providing oral health education and basic dental care to children with special needs in the Mumias District, Western Province, Kenya. Included is the preparation for the project, outline of programme of activity, findings and discussion about oral health and dental care in this region of Kenya. Finally we consider future plans for this project and oral health provision in Kenya.

\section{BACKGROUND}

In January 2010 a feature article was published in the BDJ outlining the plans to provide dental education and care to AIDs orphans in rural Western Kenya through an established charity, The Akhonya Trust. ${ }^{1}$ Due to unforeseen circumstances the Akhonya Trust was unable to support the dental project and a new host was found; consequently the project has now changed its name to Smile Mumias.

Mumias is a town with a population of approximately 91,500, in the District of Butere-Mumias in the Western Province of Kenya. The main employer of the area is Mumias Sugar, an organisation that manufactures and sells sugar grown in the surrounding area and is responsible for 60\% of Kenya's sugar production. Smile Mumias was organised in collaboration with the Mumias Education, Assessment and Resource Centre (EARC), a charity-funded government department which provides support for children with disabilities and their families in Mumias and the surrounding districts. EARC supports an extensive range of disabilities and has strong links with all the Special Units within schools and community centres in the district, and so was an ideal base for the project.

${ }^{1} \mathrm{SHO}$ in Paediatric and Special Care Dentistry, Leeds Dental Institute and York and North Yorkshire Salaried Dental Service

Email:sophy.barber@googlemail.com
The aims of Smile Mumias are to:

- Provide oral health education (OHE) to children in the Mumias District, focusing on those with special needs

- Train local caregivers and healthcare workers in oral hygiene instruction (OHI) and OHE

- Where possible, provide basic dental care (extractions and restorations) to those most in need

- Plan for future sustainable dental services in Mumias district.

\section{PREPARATION}

Communication and planning for Smile Mumias was established through Martin Nafukho, an occupational therapist at EARC. Following discussion it was agreed that a preliminary visit in January 2011 would enable assessment of both the needs of the community and resources in the area. Over 12 months, planning was undertaken via email with staff at EARC, money was raised and equipment collected. Money raised was used, along with personal funding, to buy the disposable items and to assist with costs once in Kenya, such as use of a surgery, paying the staff that assisted the project and buying further disposable equipment as needed. Most of the equipment taken was kindly donated to the project, and any other equipment which was needed was borrowed for this first visit.

\section{PROGRAMME}

EARC was used as a base for the project from which outreach could be undertaken at local schools and Special Units. An initial planning meeting at EARC allowed the recruitment of a local dental technician to assist the project (similarly qualified to a dental therapist in the UK), and enable a programme to be devised to provide care at all the various units:

- St. Angela's Deaf School for Girls boarding school for approximately 500 secondary-age girls with hearing impairment

- St. Martin's Primary School for the Deaf - Mixed boarding school for primary school age children. Equipped for around 200 children but actually provides for over 500 so it is very overcrowded

- Matunga School with Special Unit for Disabilities - a unit within a school which specifically provides for 48 children with severe special needs. A further 12 children with milder special needs are integrated into mainstream school

- Butere Special Unit for Children with Mental Disabilities - a unit which provides for approximately 20 children aged 7-18 years old with a range of mental disabilities

- Lung'anyiro School with Special Unit for Physically Disabled - a unit providing care for 22 children with physical disabilities. 


\section{FEATURE}

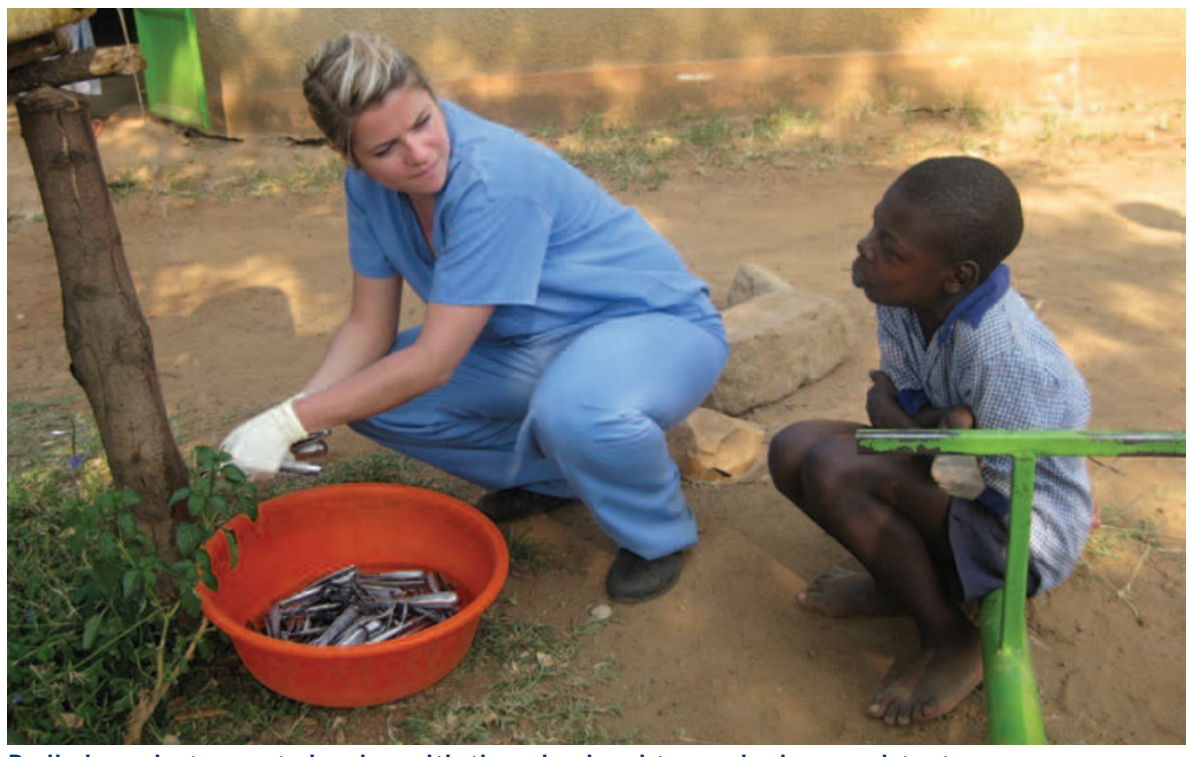

Preliminary instrument cleaning with the schoolyard tap and a keen assistant

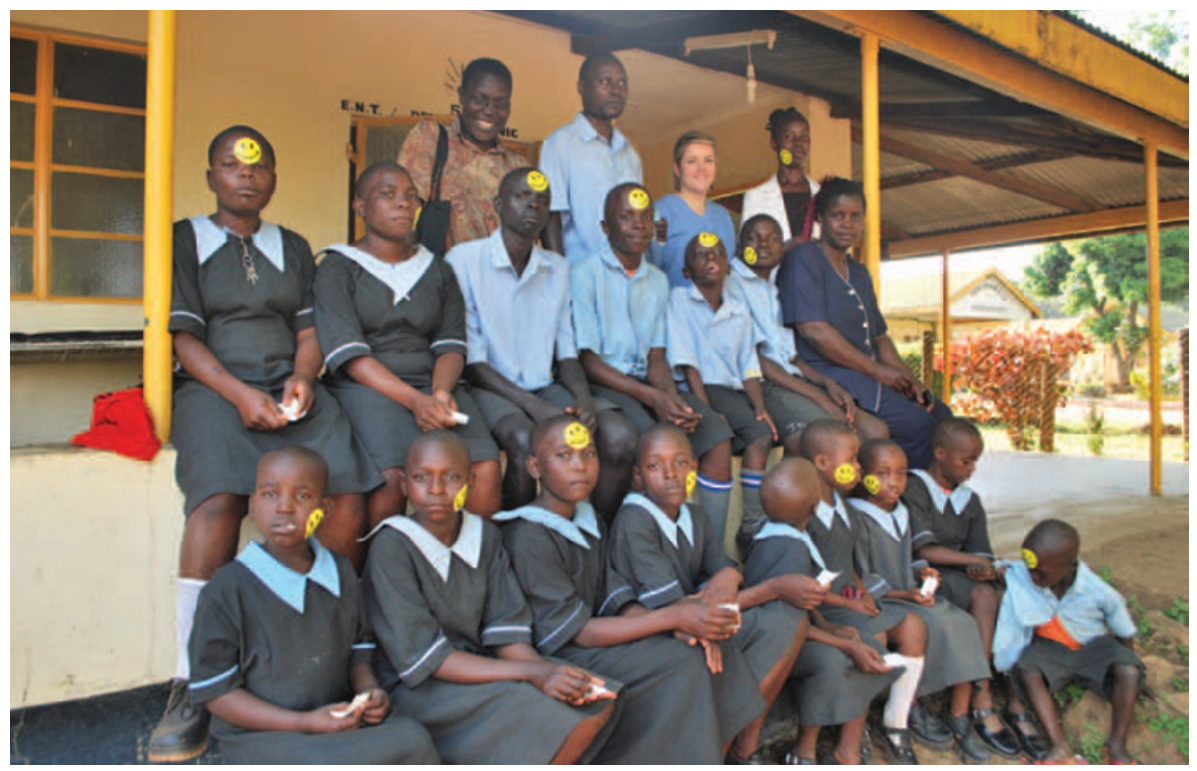

Children from the School for the Deaf following dental extractions

At each site the children were given oral health education, including information about causes and prevention of dental disease, oral hygiene instruction and a free toothbrush. The children were then screened and if any grossly carious teeth were identified these were extracted with local anaesthetic. Unfortunately, the overwhelming level of disease and lack of equipment meant that no restorative treatment could be performed and treatment was limited to extractions.

At the schools, priority was given to the children with special needs and once these children had been seen the service was extended to any other children with pain or infection. In total, over the six days of clinical activity approximately 700 children, including approximately 200 with
Understanding of dental disease and its causes was poor; when questioned about dietary causes of decay the children often could not identify which foods will contribute to caries and in many cases the children actually thought soda (carbonated drinks) was good for their teeth! Although there was a general understanding that 'sweets' are cariogenic, no association was made between sugar in other foods and caries. Conversely, most of the children identified the need to brush teeth daily with toothpaste, many stating that teeth should be brushed at least three times a day after meals.

Despite the majority of the children having never seen a dentist before, or only for extractions with or without local anaesthetic, the general level of cooperation was excellent. All children who were identified as needing an extraction were happy to accept the treatment with local anaesthetic alone, regardless of their disability or previous experience. Where multiple teeth needed extraction, treatment was undertaken in two visits, one per side.

\section{DISCUSSION}

The high caries rate found in these children is likely to be a result of many factors: a cariogenic diet, limited fluoride exposure, poor oral hygiene and medical factors.

Mumias relies heavily on the sugar industry for survival and sugar cane is the main crop in the area, readily available as a cheap source of energy. There is a strong belief in Kenya that sugar cane helps to strengthen teeth and while some studies indicate that long-term ingestion of sugar cane may increase the caries risk, ${ }^{2}$ others have indicated that unrefined sugar cane may have a protective role by inhibiting cariogenic bacteria., ${ }^{3,4}$ It is therefore difficult to establish whether the high consumption of sugar cane is significant in the development of dental caries in these children. However, Western influence has led to a considerable increase in the consumption of unrefined sugars and this is undeniably a major factor in the rapid increase in caries.

Fluoride levels vary considerably across Kenya depending on the geochemistry affecting the river, lake or borehole source. In 2006 the World Health Organisation (WHO) reported high fluoride levels in Central Districts around 


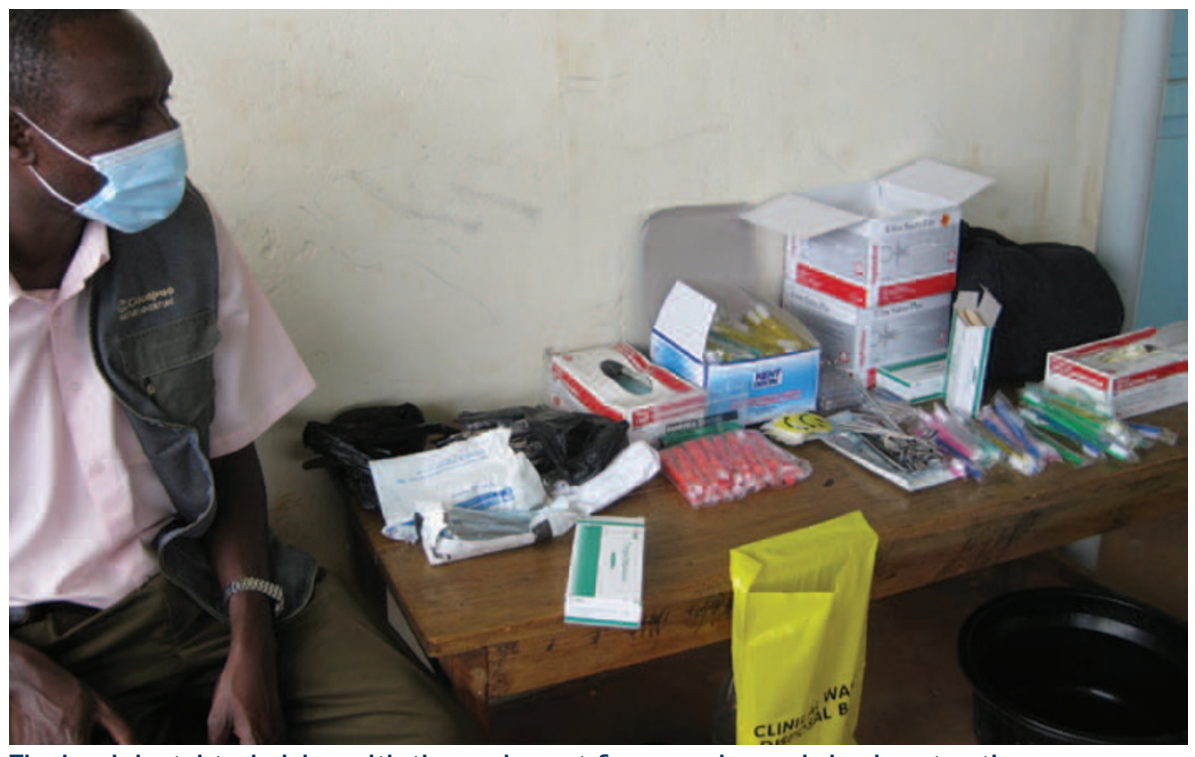

The local dental technician with the equipment for screening and simple extractions

the Rift Valley and Nairobi, with $61 \%$ of water tested exceeding $1.0 \mathrm{mg} / 1 . .^{5}$ A study in Nairobi found dental fluorosis affecting as much as $18 \%$ of primary teeth and $76 \%$ of 13-15 year olds. ${ }^{6}$ For Mumias, fluoride levels are not clearly documented and of the children examined during the screening, few showed moderate or severe fluorosis, suggesting the water fluoride levels are probably within the World Health Organisation guidelines of 0.5-1.0 mg/l. For low-income nations like Kenya, fluoride toothpaste is often the only realistic population strategy for the control and prevention of dental caries as water or salt fluoridation are not feasible due to poor infrastructure and limited financial and technological resources, and the use of topical fluoride such as fluoride varnish is impractical since it relies on repeated applications of fluoride by trained personnel on an individual basis. However a 2008 study found that 9.34 days of household expenditure is required to pay for one annual dosage of toothpaste at the lowest price in Kenya compared to just 0.015 days of expenditure in the UK, demonstrating that, while toothpaste may be available for many, it is not affordable. ${ }^{7}$ Although many of the children showed good understanding about oral hygiene and stated the need to brush up to three times a day, often oral hygiene was poor. The children were delighted to receive a free toothbrush and many stated that they had never owned a toothbrush before. This demonstrates the inability to convert knowledge into practical action where poverty is prohibitive.
Similarly it is expense which restricts access to dental care; where $22 \%$ of the population live on less than $\$ 1$ per day, a simple extraction in Mumias at the cost of $\$ 2.37$ (200KES) is unaffordable. While it is theoretically possible to access a dentist or dental technician, as most hospitals employ a dentist for at least one session a week to provide emergency care for people with dental problems, few can pay this. Furthermore, regular dental attendance is restricted as there are only around 1,340 dental personnel in Kenya which is less than 0.5 dentists per 100,000 population. ${ }^{8}$

The prevalence of serious infections such as HIV and malaria in Kenya has a significant impact on health and the use of health resources. UNAIDS estimated 1.5 million people in Kenya are HIV positive ${ }^{9}$ and that only $32 \%$ of children and $48 \%$ of the total population of people affected by HIV are receiving treatment. ${ }^{10}$ The burden of providing effective treatment for HIV both on an individual and national level dictates much of the allocation of healthcare resources. Malaria impacts both through mortality, estimated to be 74 deaths per 100,000 in 2006, and the disability caused by cerebral malaria. For under-five-yearolds only $39 \%$ are sleeping under insecticide treated mosquito nets and $24 \%$ receive anti-malarial treatment. ${ }^{8}$ Many of the children I met through EARC attributed their disability to childhood malaria.

Smile Mumias aims to focus initially on children with special needs and during this visit over 200 children with a range of disabilities were screened. The

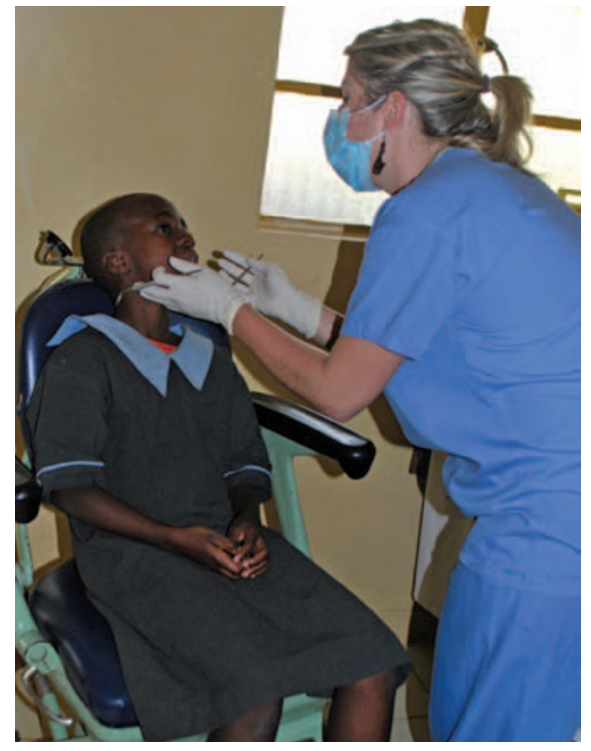

Screening in the hospital dental surgery

Kenya National Survey for Persons with Disabilities (KNSPWD) in 2008 found that nationally $4.6 \%$ of people have some form of disability, and that the majority of these live in rural areas. In Western Province the disability rate is estimated to be approximately 3.3\%. The most common disability is physical, followed by visual impairment then hearing impairment. As is the case in many countries, disability is a barrier to healthcare: while 53.5\% of disabled people in Western Province feel that they have needed healthcare, only $20.2 \%$ received it. The KNSPWD survey found that it is the attitude to disability rather than the actual impairment which impacts significantly on those affected. ${ }^{11}$ Through anecdotal information gained through EARC, several factors for this discrimination were identified:

- Traditional cultural beliefs that disability is a curse

- Poverty in family and the necessity of every family member to provide an income

- A lack of understanding and resources, such as over-subscribed schools like St. Martins.

The work undertaken by bodies such as EARC is essential to support those with disabilities and their families and overcome prejudice towards impairment.

\section{THE FUTURE}

Oral health education is likely to have a limited effect in rural Kenya where sugar provides a much-needed source of energy and toothpaste is unaffordable for many 
families. Similarly it must be acknowledged that there is little evidence to support the efficacy of short-term volunteering programmes, and while individuals may have benefited from this project, little long-term gain is likely.

Long-term equitable dental care is dependent on the empowerment of local people, involving them in decision making and delivery at ground level. Ultimately, more dental professionals are required to provide accessible and affordable care across Kenya, and changes need to be made on a national level to increase awareness and improve the resources assigned to dental care. The unaffordability of toothpaste can be addressed in many ways such as equitable pricing, use of cheaper ingredients and packaging, local production and reduction in taxes. ${ }^{7}$ Changes such as these are not possible within the scope of individual organisations, but a combined effort of those with influential power would make a huge difference.

In the short term, Smile Mumias hope to continue to accessing more schools and providing both oral health education, and screening and dental care. However, the long term goal must focus on collaborating with other existing charities to establish a programme for educating and training local people to provide dental care to alleviate pain and infection. It is hoped that a local dental professional will get involved in the project and take over management once a successful programme and reliable funding have been established.

Many thanks to all those who have supported the project so far through donations and sponsorship, and to Martin Nafukho and his team at EARC who worked tirelessly with me to make this project possible.

1. Barber S. The Akhonya Dental Project: a new charity aiming to provide oral health education and preventative care in Kenya. Br Dent J 2010; 208: 39-40.
2. Frencken J E, Rugarabamu P, Mulder J. The effect of sugar cane chewing on the development of dental caries. J Dent Res 1989; 68: 1102-1104.

3. Takara K, Ushijima K, Wada K, Iwasaki H, Yamashita $M$. Phenolic compounds from sugarcane molasses possessing antibacterial activity against cariogenic bacteria. J Oleo Sci 2007; 56: 611-614.

4. Singh A, Evans R W. Is raw sugarcane cariogenic? 45th Annual Meeting of Australian/New Zealand Division of the International Association for Dental Research (September 25-28, 2005).

5. Fawell J, Bailey K, Chilton J, Dahi E, Fewtrell L, Magara Y. Fluoride in drinking water. Geneva: World Health Organization, 2006.

6. Ng'ang'a P M, Valderhaug J. Prevalence and severity of dental fluorosis in primary schoolchildren in Nairobi, Kenya. Community Dent Oral Epidemiol 1993; 21: 15-18.

7. Goldman A S, Yee R, Holmgren C J, Benzian H. Global affordability of fluoride toothpaste. Health and Development 2008; $4: 7$.

8. World Health Organization. World health statistics 2010. Geneva: WHO, 2010.

9. UNAIDS. Global report. UNAIDS report on the global AIDS epidemic. 2010. Geneva: UNAIDS, 2010.

10. WHO/UNAIDS/UNICEF. Towards universal access: scaling up priority HIVIAIDS interventions in the health sector. Geneva: WHO, 2009.

11. National Coordinating Agency for Population and Development. Kenya national survey for persons with disablilities: preliminary report. Nairobi: National Coordinating Agency for Population and Development, March 2008 